\title{
Effects of extracorporeal shock wave therapy on plantar pressure distribution of patients with epin calcanei
}

\author{
Zehra Betül Karakoc*, Zübeyir Sarı, Eren Timurtas and Mine Gülden Polat \\ Department of Physiotherapy and Rehabilitation, Marmara University, Turkey
}

\begin{abstract}
Purpose: This study aimed to determine the alteration of plantar pressure distribution of patients with epin calcanei diagnosis after Extracorporeal Shock Wave Therapy (ESWT).

Methods: This study was completed between May and November 2015. A total of 112 patients diagnosed with epin calcanei were invited to participate. After screening, 22 patients met the inclusion criteria. Participants were treated with three sessions of ESWT at the Yavuz Selim Hospital. Pain levels and plantar pressure distribution were assessed using Visual Analog Scale (VAS) and EMED ${ }^{\circledR}$ pedobarographic system, respectively, before and after four weeks of treatment. The main outcome measures were VAS scores and max force and contact area.
\end{abstract}

Results: VAS scores decreased after treatment $(p<0.05)$. Maximum force and contact area values of total foot and forefoot increased $(p<0.05)$.

Conclusions: We consider that increased max force value of total foot and forefoot area after ESWT is due to normal walking rate gained related to decreased pain. ESWT treatment may have positive effects on foot pressure distribution and body biomechanics.

\section{Introduction}

Epin calcanei is an intramembranous ossification which occurs predominantly in the plantar fascia [1]. Continuous and extreme loading of small foot muscles [2] infectious diseases and trauma [3], age, and weight [4] are factors that increase the generation of epin calcanei. Previous studies found that the epin calcanei line is vertical [5] and that epin calcanei acts as a stressor because it is located deep within the ligament. Epin calcanei is formed because of weight bearing. While the prevalence of epin calcanei ranges between $25 \%$ and $38 \%$ [6-8] $11 \%-16 \%$ of this are asymptomatic [8,9]. Although epin calcanei occurs asymptomatically, it may increase after clinical symptoms or vice versa [10].

Extracorporeal shock wave therapy (ESWT) is a commonly carried out because of its high success rates on patients with epin calcanei [1113]. ESWT is superior to other conservative treatments in terms of low side effects, short treatment duration, non-invasiveness, outpatient use and cheapness [9]. Although the net mechanism of ESWT is unknown, it affects cells and biomolecular functions [14] by increasing tissue regeneration and neovascularization [15]. ESWT in the treatment of heel pain is suggested before surgery, after NSAI, orthotic 59 materials, and steroid injections in terms of application rankings [9].

Many devices such as pedobarography have been used to evaluate plantar pressure distribution in heel pain [16-18]. The pedobarography system is a platform with pressure sensors that measure maximum force, peak pressure, contact area, and contact time values of four-foot areas. These areas are the toes and the hind, middle, and fore areas; the total value of these parameters can be obtained as well [10].

In epin calcanei, the hind foot is painful. In this case, the loading on the hind foot can be prevented by distributing foot biomechanics and changing walking pattern. The aim of our study is to assess plantar pressure distribution after heel pain therapy with patients with epin calcanei.

\section{Materials and methods}

Participants who had been diagnosed with epin calcanei radiologically and determined to receive ESWT were included in this study, which was conducted in Yavuz Selim Public Hospital. Participants should meet the inclusion criteria as follows: diagnosis of epin calcanei radiologically, did not having receive steroid or other medical treatment, and did not receive any treatment for heel pain in the last 6 months. Exclusion criteria include lower extremity deformity, direct trauma on the heel region in the last 6 weeks, visual impairments, active infection, open sore, widespread inflammation, and epin calcanei in both feet.

Among the 112 patients invited to this study, only 22 patients participated in all evaluations (Figure 1). All the patients signed informed consent form before first evaluation. ESWT treatment was applied for three sessions every other day (each 2,000 impulses at a pressure of 2-3 bars and a frequency of $15 \mathrm{~Hz}$ ) in the prone position. The second evaluation was performed 4 weeks after cessation of treatment. Pain intensity and plantar pressure distribution of the patients were assessed by visual analog scale (VAS) and EMED pedobarography device, respectively. Mats were laid on both sides of

*Correspondence to: Zehra Betül Karakoç, Department of Physiotherapy and Rehabilitation, Marmara University, Turkey, E-mail: fztbetulmarmara@gmail.com

Key words: epin calcanei, plantar pressure, extracorporeal shock wave therapy, ESWT, heel pain

Received: February 26, 2018; Accepted: July 26, 2018; Published: July 30, 2018 


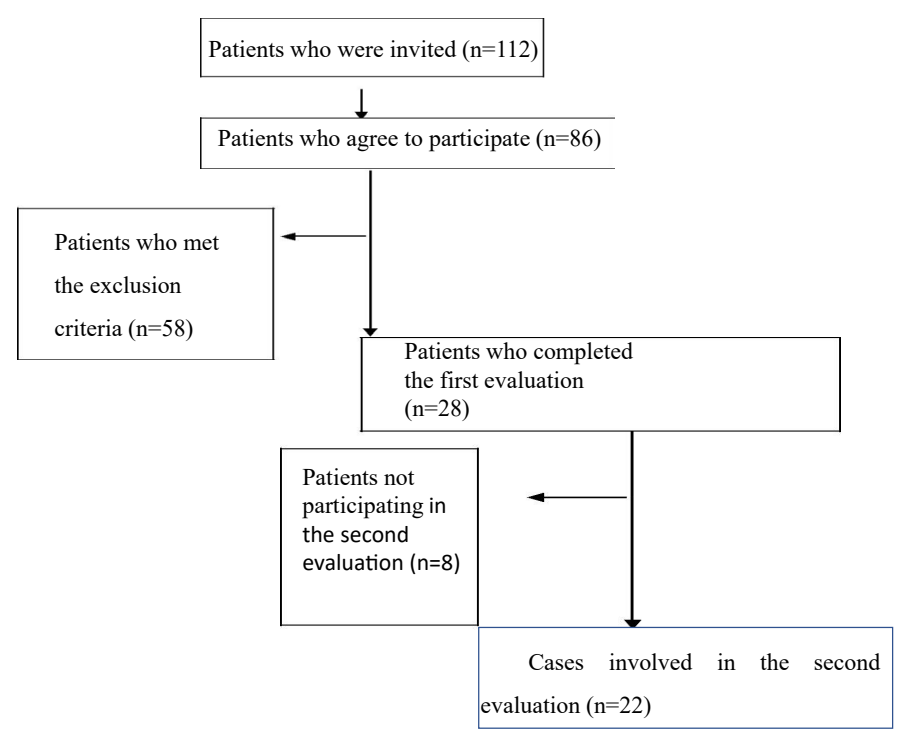

Figure 1. Flow diagram of the participants

the pedobarography device, and patients were requested to walk $3 \mathrm{~m}$ at normal speed. Pedobarography values were calculated by taking the average of five repeated measurements $[19,20]$. Then, patients were given 5 seconds of rest periods between each assessment. Assessments pressed by doubts, change in walking speed, or step adjustment according to the device were canceled, and patients were asked to walk again. After the second evaluation, physiotherapist provided advices regarding exercise and shoe type.

\section{Statistical analysis}

The demographic characteristics of the participants were identified (age, height, weight, and BMI), and pain intensity, maximum force, peak pressure, and contact area values were calculated before and after the treatment. Statistical Package for Social Sciences (SPSS) version 11.5 was used for data analysis. Wilcoxon Signed-Rank test was used for pairwise comparisons of data (Figure 1).

\section{Results}

A total of 22 patients were included in this study, including nine males and 13 females. Patients' characteristics are shown in Table 1. A significant decrease in pain intensity and increase in "total max force" $(p<0.005)$, "total contact area" $(p<0.039)$, fore foot "max force" ( $p$ $<0.017)$, and fore foot "contact area" $(p<0.024)$ was observed after treatment according to pretreatment (Table 2). The pre-treatment comparison of the healthy and affected feet showed that the peak pressure value of the affected foot was more than the healthy foot ( $p$ $<0.049)$. No significant differences were found for other evaluations before treatment $(p>0.05)$. Moreover, no significant differences were found between healthy and affected feet parameters after treatment $(p$ $>0.05$ ) (Tables 1 and 2).

\section{Discussion}

The aim of this study was to determine the change in plantar pressure distribution that could be affected because of heel pain after treatment. The most important results of this study were the increase in total maximum force, total contact area, fore foot maximum force, and fore foot contact area and pain reduction after treatment. Despite the increase in the total and fore foot maximum forces after treatment, no significant differences were found in any region of the foot in terms of maximum force between the healthy and affected feet before and after treatment. The increase of the total and heel max force values of the affected foot (after treatment) may indicate an asymmetric contact time between the affected and healthy foot before treatment. However, given the deficient contact time value, the accuracy of our findings was not finalized. We consider that the total maximum force increase can be due to the maximum force increment in the forefoot region of the affected foot, and the maximum force increase in the healthy foot can be due to the shortened contact time of the healthy foot. Sullivan et al. (2015) studied 198 patients with heel pain, examined plantar loading during walking, and found that the maximum force values of the heel and medial forefoot are less than the control group values. This result differs from our study in terms of maximum force change zone [16].

No significant differences were found between the healthy and affected feet in terms of contact area before treatment. Total foot and forefoot contact area values increased after treatment. Strain occurs in the plantar facia at the end of the stance phase, which can trigger pain. Hence, one can avoid loading on the forefoot to reduce pain from spreading during the end of the stance phase. The changes of the fore foot contact area value of healthy and affected foot after eliminating pain, suggesting that avoid walking is caused by pain. In addition, the increase in the value of forefoot contact area has led to an increase in the value of the total foot contact area.

Walking speed increases the value of heel peak pressure [21-24], and increased peak pressure value causes deformities [25]. In our study, the peak pressure value of the affected foot was higher than the healthy foot before treatment. Hence, one can strike its heel faster on the affected side to avoid pain; this phenomenon creates higher peak pressure on the heel. After eliminating pain, the absence of a significant difference between the heel peak pressure value of both feet can result from having similar contact time values in both feet.

Köse et al. (1998) [26] reported that $60 \%$ of the cases with heel pain have epin calcanei, and the calcaneal inclination angle of the $70 \%$ of the cases was under $20^{\circ}$. Reduced calcaneal inclination angle decreases the peak pressure value of the heel [27]. On this basis, we expect the heel pressure to be low in patients with epin calcanei, but the results of our study do not support this expectation. In addition, while Sullivan et al. (2015) reported that the heel peak pressure value in the anteromedial region of the cases with heel pain was higher than that of control group, Ribeiro et al's (2011) study on cases with plantar fasciitis did not report a significant difference between cases with plantar fasciitis and the healthy group in terms of heel peak pressure. In any of these studies, the peak pressure of the affected foot is not less than the healthy foot or healthy person [16].

Tuna and Serbest stated that ESWT applied on the heel is effective from the 1st week to 3rd month [28,29]. Yalçın et al. (2012) performed ESWT with 2,000 stimuli on 108 patients once a week for 5 weeks. They reported that $66 \%$ of patients' pain reduced completely and $15 \%$ decreased by $50 \%$. In our study, only one patient (4\%) had complete pain reduction, seven (31\%) had pain decreased by $50 \%$ after treatment, and eight had pain level declined by $50 \%$ or more [9].

Table 1. Demographic data of the patients

\begin{tabular}{|c|c|}
\hline Gender & $13 / 9$ \\
\hline (Female/Male) & - \\
\hline Age (year) & $55.45 \pm 1.01$ \\
\hline Weight (kg) & $84 \pm 10.12$ \\
\hline Height (cm) & $165.61 \pm 7.97$ \\
\hline BMI (kg/cm $\left.{ }^{2}\right)$ & $29.66 \pm 5.55$ \\
\hline
\end{tabular}

SD: Standard Deviation, BMI: Body Mass Index 
Table 2. Comparison of pre and post treatment values of affected foot

\begin{tabular}{|c|c|c|c|c|c|c|c|c|}
\hline & VAS & MaxForceTotal & MaxForceHind & MaxForceMid & MaxForceFore & MaxForceToes & PeakpressTotal & PeakPresHind \\
\hline & & $(\mathbf{N})$ & $(\mathbf{N})$ & $(\mathbf{N})$ & $(\mathbf{N})$ & $(\mathbf{N})$ & (kPa) & $(\mathbf{k P a})$ \\
\hline Pretreatment & $7.25 \pm 1.98$ & $1632.29 \pm 368.68$ & $507.47 \pm 101.97$ & $202.44 \pm 117.53$ & $739.68 \pm 123.09$ & $215.07 \pm 81.33$ & $385.00 \pm 128.25$ & $257.5 \pm 66.03$ \\
\hline Post-treatment & $4.50 \pm 2.25$ & $1717.37 \pm 188.29$ & $503.50 \pm 82.76$ & $219.39 \pm 118.64$ & $760.72 \pm 103.65$ & $228.99 \pm 80.57$ & $360.00 \pm 127.14$ & $250 \pm 52.28$ \\
\hline p & 0.001* & $0.005^{*}$ & 0.14 & 0.527 & $0.017^{*}$ & 0.638 & 0.474 & 0.586 \\
\hline \multirow[t]{2}{*}{$\mathrm{z}$} & -3.300 & -2.808 & -1.477 & -0.633 & -2.386 & -0.471 & -0.716 & -0.544 \\
\hline & $\begin{array}{l}\text { PeakPresMid } \\
\text { (kPa) }\end{array}$ & $\begin{array}{l}\text { PeakPresFore } \\
(\mathrm{kPa})\end{array}$ & $\begin{array}{l}\text { PeakPresToes } \\
(\mathrm{kPa})\end{array}$ & $\begin{array}{c}\text { ConAreaTotal } \\
\left(\mathrm{cm}^{2}\right)\end{array}$ & $\begin{array}{l}\text { ConAreaHind } \\
\left(\mathrm{cm}^{2}\right)\end{array}$ & $\begin{array}{c}\text { ConAreaMid } \\
\left(\mathrm{cm}^{2}\right)\end{array}$ & $\begin{array}{l}\text { ConAreaFore } \\
\left(\mathrm{cm}^{2}\right)\end{array}$ & $\begin{array}{c}\text { ConAreaToes } \\
\left(\mathrm{cm}^{2}\right)\end{array}$ \\
\hline Pretreatment & $150.00 \pm 38.01$ & $320.00 \pm 82.60$ & $317.50 \pm 168.76$ & $160.40 \pm 14.07$ & $38.27 \pm 3.80$ & $35.34 \pm 6.56$ & $58.72 \pm 6.13$ & $27.37 \pm 5.38$ \\
\hline Post-treatment & $147.50 \pm 39.02$ & $330.00 \pm 91.56$ & $332.50 \pm 153.81$ & $161.71 \pm 12.08$ & $38.16 \pm 3.54$ & $34.93 \pm 6.11$ & $59.67 \pm 5.68$ & $29.06 \pm 5.17$ \\
\hline p & 0.432 & 0.248 & 0.974 & 0.039* & 0.299 & 0.758 & $0.024^{*}$ & 0.485 \\
\hline $\mathbf{z}$ & -0.786 & -1.154 & -0.032 & -2.062 & -1.039 & -0.308 & -2.256 & -0.698 \\
\hline
\end{tabular}

Wilcoxon signed-rank test $* p<0.05, \mathrm{~N}=$ Newton, $\mathrm{kPa}=$ KiloPascal.

Low pain reduction in other cases may suggest fracture in the epin area. Fracture through the epin calcanei may reduce the effect of ESWT [1]. This is also an issue to be examined, and more studies investigating fracture in the region of the epin calcanei should be done in the future.

Absence of a control group, limited number of cases, and inhomogeneity of the time between diagnosis and treatment are limitations of our study. Given that there was no standard about pedobarographic evaluation of healthy cases [25], we could not compare cases with epin calcanei and healthy individuals.

\section{Conclusion}

We found that impaired plantar pressure distribution due to pain was improved. This improvement was maintained during the four weeks. We consider that increased max force value of the total foot and forefoot areas after ESWT may increase due to gained normal walking rate related to decreased pain.

The alteration of plantar pressure distribution was maintained 4 weeks after the treatment, but more studies are needed to investigated the long-term effects of ESWT on plantar pressure distribution. Further studies should include a large sample size, focus on associated muscle strength and ankle instability, and investigate the improvement of symptoms according to the etiological causes in the treatment of pain combined with gait analysis. In addition, shoe evaluations should be considered in future studies because of the high incidence of inadequate shoe usage by adults [29].

\section{Ethical approval}

Our study was approved by the ethics committee of Marmara University, Institute of Health Science.

\section{Funding}

This study did not receive any specific grant from funding agencies in the public, commercial, or not-for-profit sectors.

\section{Conflict of interest}

There is no conflict of interest to declare.

\section{Acknowledgments}

There is no role of study sponsors in the study design; in the collection, analysis and interpretation of data; in the writing of the manuscript; and in the decision to submit the manuscript for publication. We thank Ilgin Buyukkurt for editing our manuscript.

\section{References}

1. Smith S, Tinley P, Gilheany M, Grills B, Kingsford A (2007) The inferior calcaneal spur-anatomical and histological considerations. The Foot 17: 25-31.

2. Bachmann CE, Gruber G, Konermann W, Arnold A, Gruber GM, et al. (2012) Ultrasound imaging of the musculoskeletal system. Springer Science and Business Media

3. DuVRIES HL (1957) Heel spur (calcaneal spur) AMA Archives of surgery 74: 536-542.

4. Serbest MO, Kaya Hİ, Demir MH, Ercan S, Çetin C (2013) Comparison of effectiveness of the extracorporeal shock wave therapy (ESWT) and steroid injection at plantar fasciitis treatment. Medicina Sportiva. Journal of Romanian Sports Medicine Society 9: $2185-2190$.

5. Li J, Muehleman C (2007) Anatomic relationship of heel spur to surrounding soft tissues: greater variability than previously reported. Clinical Anatomy 20: 950-955.

6. Weiss E (2012) Calcaneal spurs: examining etiology using prehistoric skeletal remains to understand present day heel pain. Foot (Edinb) 22: 125-129. [Crossref]

7. Toumi H, Davies R, Mazor M, Coursier R, Best TM, et al. (2014) Changes in prevalence of calcaneal spurs in men \& women: a random population from a trauma clinic. $B M C$ Musculoskelet Disord 15: 1471-2474 [Crossref]

8. Kristian Jarl Johan Johansson, Janne Julius Sarimo, Lasse Lennart Lempainen, Tiina Laitala-Leinonen, and Sakari Yrjö Orava (2012) Calcific spurs at the insertion of the Achilles tendon: a clinical and histological study. Muscles Ligaments Tendons J 2: 273277. [Crossref]

9. Yalcin E, Akca AK, Selcuk B, Kurtaran A, Akyuz M (2012) Effects of extracorporal shock wave therapy on symptomatic heel spurs: a correlation between clinical outcome and radiologic changes. Rheumatol Int 32: 343-347. [Crossref]

10. Birtane M, Tuna H (2004) The evaluation of plantar pressure distribution in obese and nonobese adults. Clin Biomech (Bristol, Avon) 19: 1055-1059. [Crossref]

11. Moretti B, Garofalo R, Patella V, Sisti GL, Corrado M, (2006) Extracorporeal shock wave therapy in runners with a symptomatic heel spur. Knee Surg Sports Traumatol Arthrosc 14: 1029-1032. [Crossref]

12. Angela Notarnicola, Biaggio Moretti (2012) The biological effects of extracorporeal shock wave therapy (eswt) on tendon tissue. Muscles Ligaments Tendons J 2: 33-37. [Crossref]

13. Lizis P (2014) Comparison of short-term analgesic effects of extracorporeal shock wave therapy (ESWT) and conservative treatment (CT) in men with chronic heel spur (HS). International Journal of Medicine and Medical Research.

14. Mittermayr R, Hartinger J, Antonic V, Meinl A, Pfeifer S, et al. (2011) Extracorporeal shock wave therapy (ESWT) minimizes ischemic tissue necrosis irrespective of application time and promotes tissue revascularization by stimulating angiogenesis Ann Surg 253: 1024-1032. [Crossref]

15. Orhan Z, Ozturan K, Guven A, Cam K (2004) The effect of extracorporeal shock waves on a rat model of injury to tendo Achilles. J Bone Joint Surg Br 86: 613-618. [Crossref]

16. Sullivan J, Burns J, Adams R, Pappas E, Crosbie J (2015) Plantar heel pain and foot loading during normal walking. Gait posture 41: 688-693. [Crossref]

17. Bonanno DR, Landorf KB, Menz HB (2011) Pressure-relieving properties of various shoe inserts in older people with plantar heel pain. Gait posture 33: 385-389. [Crossef] 
18. Ribeiro AP, Trombini-Souza F, Tessutti VD, Lima FR, João SM, et al. (2011) The effects of plantar fasciitis and pain on plantar pressure distribution of recreational runners. Clin Biomech (Bristol, Avon) 26: 194-199. [Crossref]

19. Hahn F, Maiwald C, Horstmann T, Vienne P (2008) Changes in plantar pressure distribution after Achilles tendon augmentation with flexor hallucis longus transfer. Clin Biomech (Bristol, Avon) 23: 109-116. [Crossref]

20. Jeans KA, Karol LA (2010) Plantar pressures following Ponseti and French physiotherapy methods for clubfoot. J Pediatr Orthop 30: 82-89. [Crossref]

21. Kirtley C (2006) Clinical gait analysis: theory and practice. Elsevier Health Sciences.

22. Segal A, Rohr E, Orendurff M, Shofer J, O’Brien M, et al. (2004) The effect of walking speed on peak plantar pressure. Foot and Ankle Int 25: 926-933. [Crossref]

23. Taylor AJ, Menz HB, Keenan AM (2004) The influence of walking speed on plantar pressure measurements using the two-step gait initiation protocol. The Foot 14: $49-55$.
24. Burnfield JM, Few CD, Mohamed OS, Perry J (2004) The influence of walking speed and footwear on plantar pressures in older adults. Clin Biomech (Bristol, Avon) 19 78-84. [Crossref]

25. Fitzgerald RH, Vedpathak A (2013) Plantar pressure distribution in a hyper pronated foot before and after intervention with an extraosseous talotarsal stabilization device-a retrospective study. J Foot Ankle Surg 52: 432-443. [Crossref]

26. Köse N, Göktürk E, Turgut A, Seber S, Hazer B (1998) Taban çöküklüğü ve topuk dikeninin topuk ağrısı etiyolojisindeki rolü. Acta Orthop Traumatol Turc 32: 322-324.

27. Nordin M, Frankel VH (2001) Basic biomechanics of the musculoskeletal system. Lippincott Williams \& Wilkins

28. Tuna S (2014) Plantar fasiitli hastalarda ekstrakorporeal şok dalga tedavisinin etkinliği ve epin boyu ile ilişkisi. Dicle Tip Dergisi 41: 337-340

29. Vass C, Edwards C, Smith A, Sahota O, Drummond A (2015) What do patients wear on their feet? A service evaluation of footwear in elderly patients. Int J Ther Rehab 22: 218.

Copyright: $@ 2018$ Karakoc ZB. This is an open-access article distributed under the terms of the Creative Commons Attribution License, which permits unrestricted use, distribution, and reproduction in any medium, provided the original author and source are credited. 